\title{
DISTAL FIBULECTOMY FOR EWING'S SARCOMA
}

\author{
F. H. NORMAN-TAYLOR, D. I. S. SWEETNAM, J. A. FIXSEN
}

From St Bartholomew's Hospital, London and Chase Farm Hospital, Middlesex, England

We treated five children with non-metastatic Ewing's sarcoma of the distal fibula by distal fibulectomy. At a mean of eight years after surgery they all had nearly normal levels of painfree function.

Distal fibulectomy is a good alternative to the more radical amputations recommended in the past.

J Bone Joint Surg [Br] 1994; 76-B:559-62.

Ewing's sarcoma is the second most common primary tumour of bone. It is probably of parasympathetic nerve origin (Horowitz, Tsokos and DeLaney 1992) and is locally and systemically invasive. Nearly all cases (90\%) occur between the ages of 5 and 30 years (Neff 1986) and $65 \%$ in the second decade of life, with an annual incidence in white people under 21 years old of 2 to 3 per million. It is very rare in other races. In most cases the tumour presents as a painful swelling and in $15 \%$ to $30 \%$ of patients also with metastases (Horowitz et al 1992). Needle aspiration biopsy is reported to be sufficient to establish a histological diagnosis in $78 \%$ of cases, but more tissue is usually required for accurate classification (Neff 1986). Fibular lesions account for about $6 \%$ of the total (Wilner 1982) with about half of these occurring distally (Toni et al 1993).

Established treatment involves a combination of chemotherapy and surgery, with or without radiotherapy. Surgical ablation of the primary tumour, either by amputation or en bloc resection, has been reported to improve long-term survival (Brown, Fixsen and Plowman 1987).

Limb-preserving surgery for tumours of the proximal fibula is well established. In the distal fibula, however, it has been accepted practice to perform an amputation, either below or through the knee (Neff 1986; Toni et al 1993). Limb-preserving surgery has rarely been performed (Marcove and Rosen 1980; Toni et al 1993) although the results of lateral talar shift and the role of the lateral malleolus in ankle stability and in weight-bearing are well documented (Ramsey and Hamilton 1976; Yablon, Heller and Shouse 1977; Goh et al 1992).

We report five cases of Ewing's sarcoma treated by simple distal fibulectomy without significant loss of function in the limb.

Table I. ISOLS scores (points) in five patients with Ewing's sarcoma treated by distal fibulectomy

\begin{tabular}{lllllllll}
\hline Case & Follow-up & Pain & Function & $\begin{array}{l}\text { Emotional } \\
\text { acceptance }\end{array}$ & Supports & Walking & Gait & Total \\
\hline 1 & 15 yr 4 mth & 5 & 3 & 3 & 5 & 4 & 3 & 23 \\
2 & 10 yr 5 mth & 5 & 5 & 2 & 5 & 5 & 4 & 26 \\
3 & 7 yr 4 mth & 5 & 5 & 2 & 5 & 5 & 4 & 26 \\
4 & 5 yr 9 mth & 5 & 5 & 3 & 5 & 5 & 5 & 28 \\
5 & 1 yr 5 mth & 5 & 5 & 3 & 5 & 5 & 5 & 28 \\
\multicolumn{2}{l}{ Mean 8 yr } & 5 & 4.6 & 2.6 & 5 & 4.8 & 4.2 & 26.2 \\
\multicolumn{2}{l}{ Maximum score } & 5 & 5 & 5 & 5 & 5 & 5 & 30 \\
\hline
\end{tabular}

F. H. Norman-Taylor, FRCS, Orthopaedic Registrar

Addenbrooke's NHS Trust, Addenbrooke's Hospital, Hills Road, Cambridge CB2 2QQ, UK.

D. I. S. Sweetnam, FRCS, Orthopaedic Registrar

University College Hospital, Gower Street, London WC1E 6AU, UK.

J. A. Fixsen, MChir, FRCS, Consultant Orthopaedic Surgeon

St Bartholomew's Hospital, West Smithfield, London EC1A 7BE, UK.

Correspondence should be sent to Mr F. H. Norman-Taylor at 100 Castle Street, Woodbridge, Suffolk IP12 1HL, UK.

(C1994 British Editorial Society of Bone and Joint Surgery $0301-620 \times / 94 / 4800 \$ 2.00$

\section{PATIENTS AND METHODS}

Between 1978 and 1991 we treated five children with non-metastatic Ewing's sarcoma of the distal fibula by a combination of chemotherapy and local excision with or without subsequent local radiotherapy. There were four girls and one boy. The average age at presentation was 11 years 3 months ( 8 years 6 months to 13 years 8 months). They all had a painful swelling above and lateral to the ankle. In every case the diagnosis was suspected radio- 

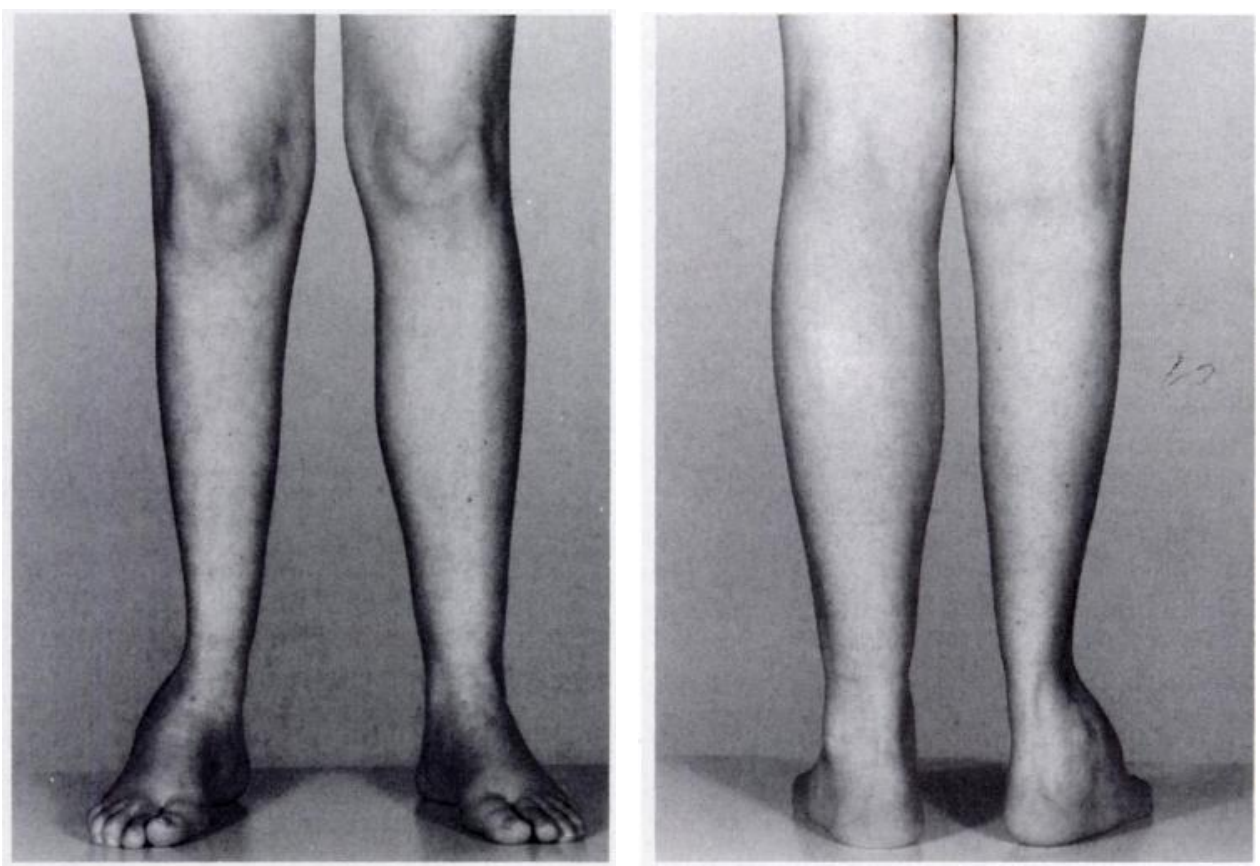

Fig. 1

Case 3. Seven years after right distal fibulectomy and local radiotherapy. There is wasting of the calf muscles and the ankle is in valgus.

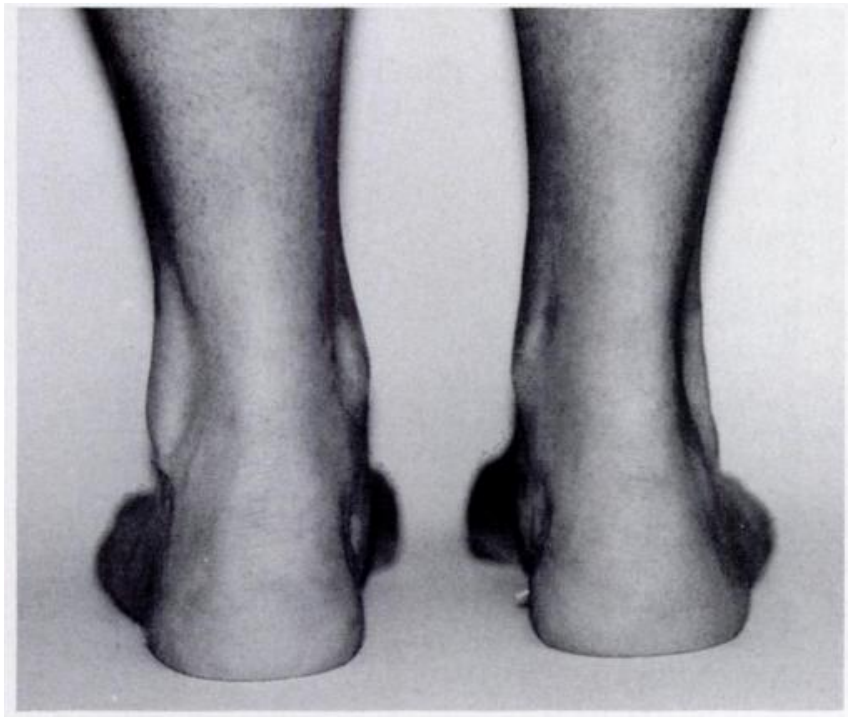

Fig. 2

Case 4. Five years after right distal fibulectomy and preservation of the peroneal muscles. The heel is in only slight valgus.

logically and confirmed histologically by open biopsy. Surgery was preceded by the chemotherapy regime accepted at the time.

Distal fibulectomy was performed under general anaesthesia through a direct lateral longitudinal incision, using a thigh tourniquet. All potentially viable structures were preserved. The peroneal muscles were preserved in one patient (case 4). Wide excision of the radiologically involved bone was undertaken in all except one (case 2) in whom the whole fibula was removed en bloc. The specimen always included the distal third of the fibula, including the lateral malleolus. No attempt was made to stabilise the joint by surgical reconstruction.

A plaster-of-Paris backslab or full cast was worn for an average of 4.5 weeks ( 2 to 8 ) and weight-bearing was then allowed. All excised specimens were sent for further histological analysis.

Postoperative radiotherapy was given to three patients as part of the therapeutic programme accepted at the time of treatment. A mean of $4800 \mathrm{cGy}$ was given in 26 fractions over 34 days. Two patients (cases 4 and 5), treated more recently, had no radiotherapy.

\section{RESULTS}

All the patients had returned to their previous levels of activity by one year. One (case 1), who had a mild spastic diplegia present from birth, developed a leg-length inequality of $2 \mathrm{~cm}$ at four years after surgery and radiotherapy. This was accompanied by a fixed equinus deformity of the foot, which did not respond to conservative treatment. A triple arthrodesis was performed six years after the fibulectomy, which corrected the foot to neutral and improved function.

The patients were followed up for an average of 8 years (1 year 5 months to 15 years 4 months). A standardised system of symptom assessment was used as recommended by the International Symposia on Limb Salvage (ISOLS) (Enneking et al 1993). All patients were found to be painfree and continued to function well 

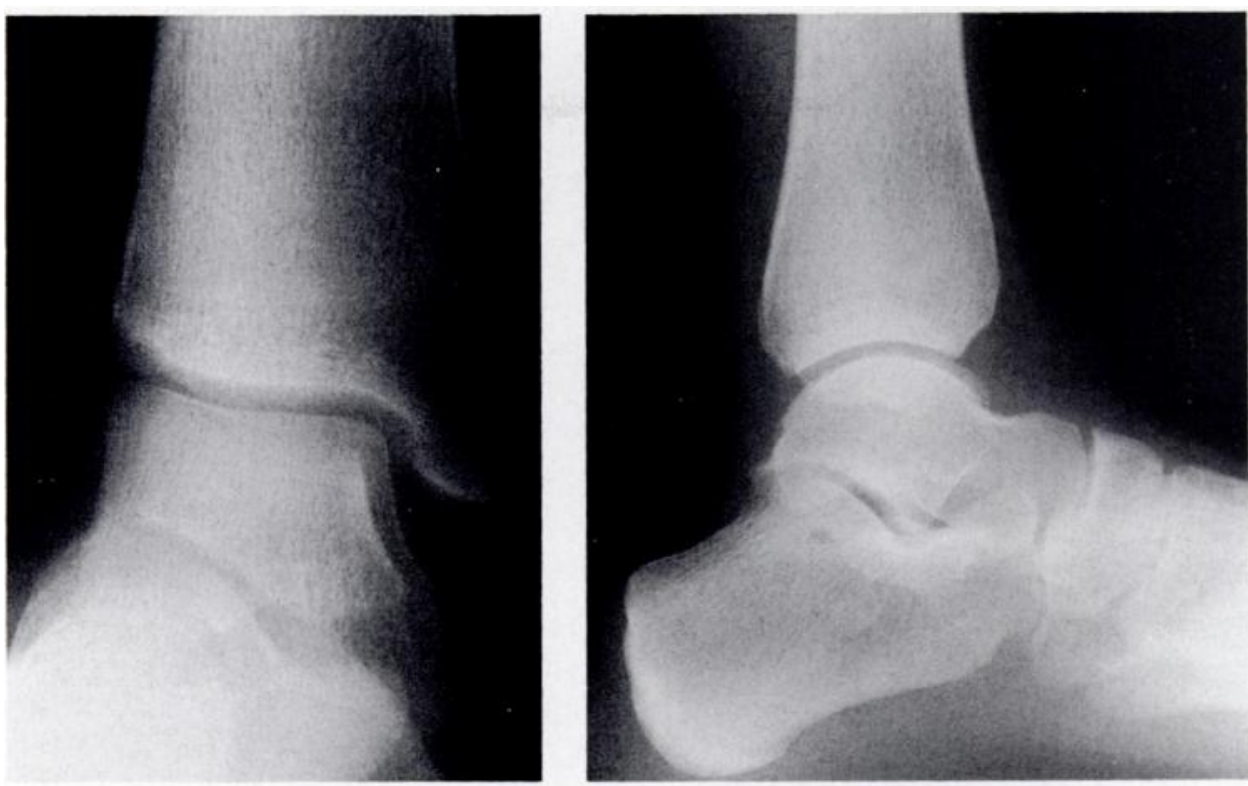

Fig. 3

Case 4. Radiological appearance five years after distal fibulectomy.

Table II. Range of passive movement in degrees (R) and muscle power (P) measured on the MRC scale of 0 to 5

\begin{tabular}{|c|c|c|c|c|c|c|c|c|}
\hline \multirow[b]{2}{*}{ Case } & \multicolumn{2}{|c|}{ Dorsiflexion } & \multicolumn{2}{|c|}{ Plantar flexion } & \multicolumn{2}{|c|}{ Inversion } & \multicolumn{2}{|c|}{ Eversion } \\
\hline & $\mathbf{R}$ & $\mathbf{P}$ & $\mathbf{R}$ & $\mathbf{P}$ & $\mathbf{R}$ & $\mathbf{P}$ & $\mathbf{R}$ & $\mathbf{P}$ \\
\hline 1 & -5 & 5 & 45 & 5 & 0 & 0 & 0 & 0 \\
\hline 2 & 0 & 5 & 80 & 5 & 0 & 5 & 30 & 0 \\
\hline 3 & -5 & 5 & 80 & 5 & 30 & 5 & 5 & 0 \\
\hline 4 & 40 & 5 & 45 & 5 & 60 & 5 & 15 & 5 \\
\hline 5 & 0 & 5 & 40 & 5 & 40 & 5 & 15 & 5 \\
\hline
\end{tabular}

without the use of external supports. The average ISOLS score was 26.2 points (23 to 28 ) out of a possible maximum of 30 (Table I).

On examination at review there was reduced calf muscle bulk in four patients (Fig. 1). In the remaining patient (case 4) in whom the peroneal muscles had been preserved, there was no measurable wasting. There was a leg-length discrepancy in only one patient as described above. When compared with the other limb, two patients had reduced power and range of movement on eversion and dorsiflexion and two on dorsiflexion and inversion; two patients had no limitation of ankle or foot movement and had full power (Table II). The reduced range of movement at the ankle, particularly dorsiflexion, appeared to account for the limp shown by three of the patients.

Examination of stance showed that the three patients with the longest follow-up stood with the ankle in valgus and a compensatory varus at the subtalar joint which allowed the foot to be plantigrade (Fig. 1). The other two patients stood with nearly normal ankle alignment (Fig. 2).
One patient (case 3) developed a lung metastasis five years after surgery, which was successfully treated by local resection and chemotherapy. She remains free from further tumour 24 months later. No patient has developed local recurrence.

Radiographs showed severe valgus of the ankle in the cases followed for 10 and 15 years (Figs 3 and 4) but up to 6 years after operation there were no degenerative changes and at 10 and 15 years there were only mild signs of degenerative arthritis.

\section{DISCUSSION}

Children and adolescents tend to score well on symptomatic scoring systems despite serious physical deformities (Coates et al 1990). All our patients have remarkable ankle stability with normal levels of painfree activity and all but one participate in sports including cycling, badminton, hockey, netball, football and competitive running.

Patients with primary malignant bone tumours are 

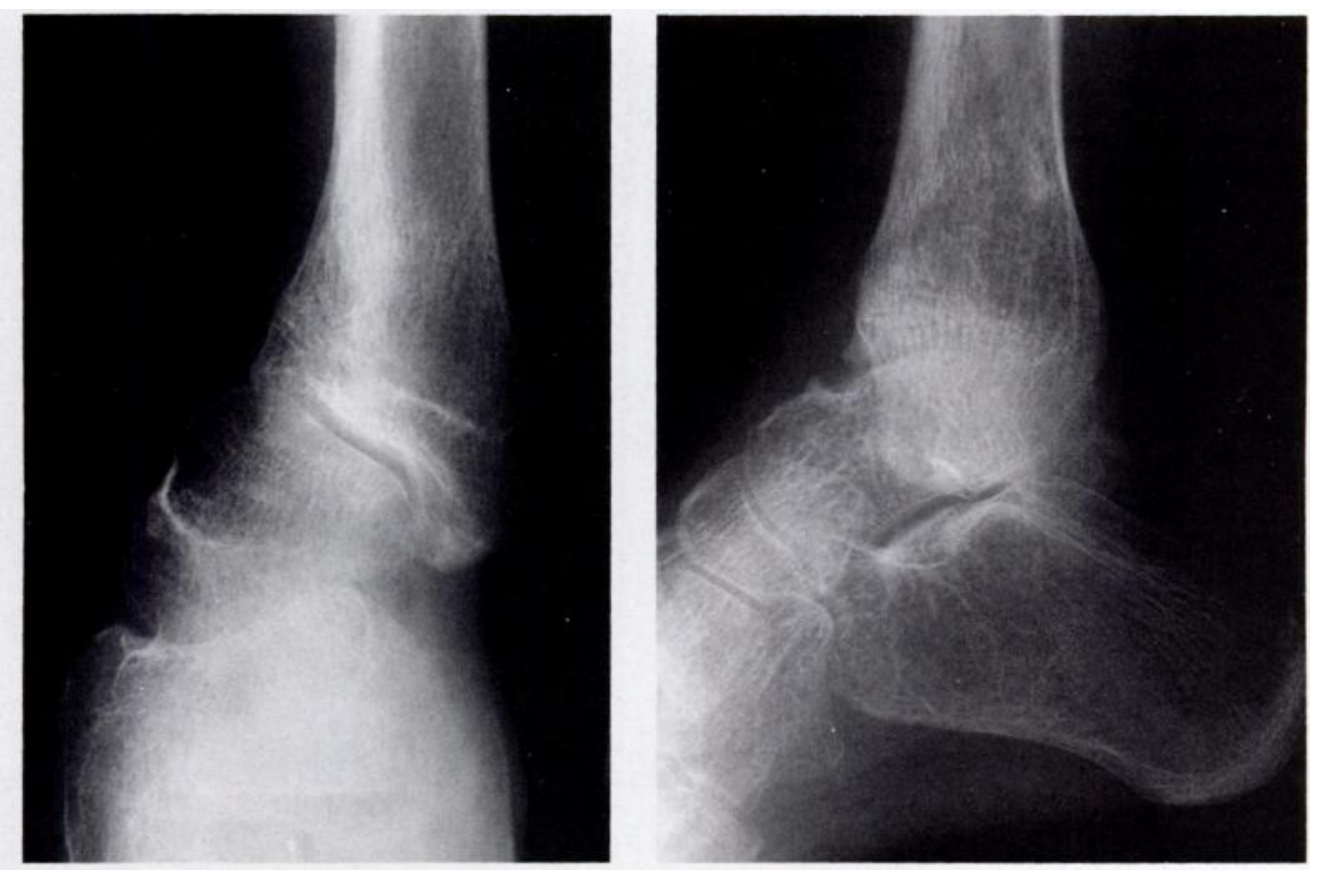

Fig. 4

Case 2. Radiological appearance ten years after distal fibulectomy and local radiotherapy.

surviving longer and their quality of life has been improved by limb-sparing surgery (Sweetnam 1989; Potma et al 1992). The patients in this series demonstrate that the lateral malleolus can be removed with remarkably little functional deficit and with no necessity for reconstruction of the ankle.

Distal fibulectomy and retention of the foot are a good alternative to the radical amputations recommended in the past.

No benefits in any form have been received or will be received from a commercial party related directly or indirectly to the subject of this article.

\section{REFERENCES}

Brown AP, Fixsen JA, Plowman PN. Local control of Ewing's sarcoma: an analysis of 67 patients. Br J Radiol 1987; 60:261-8.

Coates CJ, Paterson JMH, Woods KR, Catterall A, Fixsen JA. Femoral osteotomy in Perthes' disease: results at maturity. J Bone Joint Surg [Br] 1990; 72-B:581-5.

Enneking WF, Dunham W, Gebhardt MC, Malawar M, Pritchard DJ. A system for the functional evaluation of reconstructive procedures after surgical treatment of tumours of the musculoskeletal system. Clin Orthop 1993; 286:241-6.
Goh JCH, Lee EH, Ang EJ, Bayon P, Pho RWH. Biomechanical study on the load-bearing characteristics of the fibula and the effects of fibular resection. Clin Orthop 1992; 279:223-8.

Horowitz ME, Tsokos MG, DeLaney TF. Ewing's sarcoma. CA-Cancer$J$-Clin 1992; 42:300-20.

Marcove RC, Rosen G. En bloc resections for osteogenic sarcoma. Cancer $1980 ; 45: 3040-4$.

Neff JR. Nonmetastatic Ewing's sarcoma of bone: the role of surgical therapy. Clin Orthop 1986; 204:111-8.

Potma A, Kingma A, De Ruiter JH, et al. Quality of life in bone tumour patients comparing limb salvage and amputation of the lower extremity. J Surg Oncol 1992; 51:47-51.

Ramsey PL, Hamilton W. Changes in tibiotalar area of contact caused by lateral talar shift. J Bone Joint Surg [Am] 1976; 58-A:356-7.

Sweetnam R. Malignant bone tumour management: 30 years of achievement. Clin Orthop 1989; 247:67-73.

Toni A, Neff JR, Sudanese A, et al. The role of surgical therapy in patients with nonmetastatic Ewing's sarcoma of the limbs. Clin Orthop 1993; 286:225-40.

Wilner D. Radiology of bone tumors and allied disorders. Philadelphia and London: WB Saunders, 1982.

Yablon IG, Heller FG, Shouse $L$. The key role of the lateral malleolus in displaced fractures of the ankle. J Bone Joint Surg [Am] 1977; 59A:169-73. 